\title{
HUBUNGAN SENAM LANSIA TERHADAP KUALITAS HIDUP LANSIA YANG MENDERITA HIPERTENSI DI KLINIK SWASTA KEDATON BANDAR LAMPUNG
}

\author{
Fitria Saftarina ${ }^{1}$, Fairuz Rabbaniyah ${ }^{2}$ \\ ${ }^{1}$ Departemen Ilmu Kedokteran Komunitas, Fakultas Kedokteran Universitas Lampung \\ ${ }^{2}$ Fakultas Kedokteran Universitas Lampung \\ Email: fitria205@yahoo.co.id
}

\begin{abstract}
Correlation between Gymnastic for Elderly with Quality of Life The Elderly who suffer Hypertension at Private Clinic Kedaton Bandar Lampung. Quality of life of individuals who suffer hypertension worse than individuals who have normal blood pressure. It is influenced by blood pressure and the consciousness person's level. Improved mental quality of life obtained through physical activity is to reduce stress, increase enthusiasm and confidence, reduce anxiety and depression that were cause by disease. This study was to know the correlation of gymnastic for elderly with quality of life the elderly who suffer hypertension in clinic HC UMMI Kedaton, Bandar Lampung. This research was conducted during the month of November 2015 at the Clinic of HC UMMI Kedaton, Bandar Lampung. This study was an observational study, with cross sectional method. Total sample were 58 respondents. Chi square used to correlation analysis. The results showed the majority of the elderly who suffer hypertension have a very good quality of their life, and most of them were doing gymnastics elderly. Most of the elderly who suffer from hypertension in the Clinic of HC UMMI were female. There was a significant relationship between gymnastic elderly with quality of life the elderly who suffer hypertension $(\mathrm{p}=0.000)$.
\end{abstract}

Keywords: Elderly, Elderly gymnastic, Hypertension, quality of life

\begin{abstract}
Abstrak: Hubungan Senam Lansia terhadap Kualitas Hidup Lansia yang Menderita Hipertensi di Klinik Swasta Kedaton Bandar Lampung. Kualitas hidup individu yang menderita hipertensi lebih buruk dibandingkan dengan individu yang memiliki tekanan darah normal. Hal tersebut dipengaruhi oleh tekanan darah dan tingkat kesadaran seseorang tersebut. Peningkatan kualitas hidup secara mental yang diperoleh melalui aktivitas fisik ialah mengurangi stres, meningkatkan rasa antusias dan rasa percaya diri, serta mengurangi kecemasan dan depresi seseorang terkait dengan penyakit yang dialaminya. Penelitian ini bertujuan untuk mengetahui hubungan senam lansia dengan kualitas hidup lansia yang menderita hipertensi di Klinik HC UMMI Kedaton Bandar Lampung. Penelitian ini dilakukan selama bulan November 2015 di Klinik HC UMMI Kedaton Bandar Lampung. Desain penelitian ini adalah penelitian observasional dengan metode yang digunakan adalah cross sectional dengan sampel menggunakan sampel total dan di dapatkan 58 orang responden penelitian. Penelitian ini menggunakan analisis korelasi chi square. Hasil penelitian ini menunjukkan sebagian besar lansia yang mendertita hipertensi memiliki kualitas hidup yang sangay baik, lalu sebagian besar lansia di klinik HC UMMI Kedaton melakukan senam lansia, dan sebagian besar lansia yang menderita hipertensi adalah lansia yang berjenis kelamin perempuan serta terdapat hubungan yang signifikan $(p=0,000)$ antara senam lansia terhadap kualitas hidup lansia yang menderita hipertensi.
\end{abstract}

Kata kunci: Lansia, Hipertensi, Kualitas hidup, Senam lansia

Sampai saat ini hipertensi tetap menjadi masalah dikarenakan beberapa hal, antara lain meningkatnya prevalensi hipertensi, masih banyaknya pasien hipertensi yang belum mendapatkan pengobatan ataupun yang sudah sudah diobati tetapi tekanan darahnya belum mencapai target yang diinginkan, serta adanya penyakit penyerta dan komplikasi yang dapat meningkatkan morbiditas dan mortalitas (Yogiantoro, 2009). Berdasarkan Riskesdas Provinsi Lampung (2013), prevalensi hipertensi meningkat menjadi $24,7 \%$. Tanggamus menjadi kabupaten dengan angka angka kejadian hipertensi terbesar yaitu 31,3\%. Sedangkan angka kejadian di Bandar Lampung sebesar $20 \%$. Terdapat hubungan antara usia, obesitas, konsumsi garam, dan konsumsi makanan berlemak dengan kejadian hipertensi. Sedangkan tidak terdapat hubungan antara jenis kelamin, kebiasaan merokok, kebiasaan konsumsi alkohol, dan kebiasaan konsumsi kafein dengan kejadian hipertensi (Syahrini et al., 2012). Tekanan darah 
sistolik meningkat sesuai dengan peningkatan usia, sedangkan tekanan darah diastolik meningkat seiring dengan tekanan darah sistolik sampai sekitar usia 55 tahun, yang kemudian menurun yang diakibatkan terjadinya proses kekakuan arteri akibat aterosklerosis. Sekitar usia 60 tahun dua pertiga pasien dengan hipertensi mempunyai hipertensi sistolik terisolasi, sedangkan usia diatas 75 tahun tiga perempat dari seluruh paien mempunyai hipertensi sistolik (Suhardjono, 2009).

Kualitas hidup individu yang menderita hipertensi lebih buruk dibandingkan dengan individu yang memiliki tekanan darah normal. Hipertensi berhubungan dengan rendahnya kualitas hidup, terutama dalam domain fungsi fisik. Berdasarkan Soni et al., ( 2010), penurunan kualitas hidup berimplikasi terhadap pengobatan dan pencegahan komplikasi yang dapat menimbulkan kualitas hidup lebih parah. Fungsi sistem tubuh lansia yang mengalami hipertensi dapat berdampak buruk terhadap kualitas hidup lansia, baik dalam skala ringan, sedang, maupun berat. Hipertensi dapat mempengaruhi kualitas hidup lansia. Menurut Suardana, Saraswati dan Wiratni (2010), kualitas hidup berhubungan dengan kesehatan, suatu kepuasan atau kebahagiaan individu sepanjang dalam kehidupannya mempengaruhi mereka atau dipengaruhi oleh kesehatan.

Peningkatan kualitas hidup secara mental yang diperoleh melalui aktivitas fisik ialah mengurangi stres, meningkatkan rasa antusias dan rasa percaya diri, serta mengurangi kecemasan dan depresi seseorang terkait dengan penyakit yang dialaminya (Taylor, Sallis \& Needle, 1985). Senam yang dilakukan oleh lansia telah menunjukkan terjadi peningkatan skor kualitas hidup rata-rata, sehingga menunjukkan adanya pengaruh signifikan senam bugar lansia terhadap kualitas hidup penderita hipertensi (Setiawan, Wungouw \& Pangemanan, 2013).

\section{METODE PENELITIAN}

Penelitian ini dilakukan selama bulan November 2015 di Klinik HC UMMI Kedaton Bandar Lampung. Penelitian ini adalah penelitian observasional dengan metode cross sectional, yaitu suatu penelitian untuk mempelajari dinamika korelasi antara faktor-faktor resiko dengan efek, dengan cara pendekatan, observasi atau pengumpulan data sekaligus pada satu waktu. Artinya tiap subjek penelitian hanya diobservasi sekali saja dan pengukuran dilakukan terhadap status karakter atau variabel subjek pada saat pemeriksaan (Notoatmodjo, 2010).

Sampel yang digunakan pada penelitian ini adalah teknik total sampling. Pada penelitian ini didapatkan 58 lansia yang dijadikan sebagai responden penelitian. kriteria inklusi dalam penelitian ini adalah wanita dan pria berusia $\geq 60$ tahun, lansia yang memiliki riwayat hipertensi dan kriteria ekslusi dalam penelitian ini adalah lansia dengan keadaan kegawatdaruratan.

Alat yang digunakan dalam penelitian ini adalah kuisioner kualitas hidup SF-36.

\section{HASIL}

Responden dalam penelitian di tentukan berdasarkan teknik total sampel. Pada penelitian ini didapatkan 58 responden selama bulan November.

\section{Tabel 1. Distribusi Usia Lansia}

\begin{tabular}{lrr}
\hline \multicolumn{1}{c}{ Usia } & n & \multicolumn{1}{c}{ \% } \\
\hline $60-64$ & 23 & 40 \\
$65-69$ & 25 & 42 \\
$70-74$ & 8 & 14 \\
$75-79$ & 2 & 4 \\
\hline Jumlah & 58 & 100 \\
\hline
\end{tabular}

Tabel 2. Distribusi Kejadian Hipertensi berdasarkan Jenis Kelamin

\begin{tabular}{lrr}
\hline \multicolumn{1}{c}{ Jenis Kelamin } & n & \multicolumn{1}{c}{$\%$} \\
\hline Laki-Laki & 14 & 24 \\
Perempuan & 44 & 76 \\
\hline Jumlah & 58 & 100 \\
\hline
\end{tabular}

Tabel 3. Distribusi Frekuensi Senam Lansia

\begin{tabular}{lrr}
\hline \multicolumn{1}{c}{ Usia } & n & \multicolumn{1}{c}{ \% } \\
\hline $60-64$ & 23 & 40 \\
$65-69$ & 25 & 42 \\
$70-74$ & 8 & 14 \\
$75-79$ & 2 & 4 \\
\hline Jumlah & 58 & 100 \\
\hline
\end{tabular}

Tabel 4. Distribusi Kualitas Hidup Lansia

\begin{tabular}{lrr}
\hline \multicolumn{1}{c}{ Usia } & \multicolumn{1}{c}{ n } & \multicolumn{1}{c}{ \% } \\
\hline $60-64$ & 23 & 40 \\
$65-69$ & 25 & 42 \\
$70-74$ & 8 & 14 \\
$75-79$ & 2 & 4 \\
\hline Jumlah & 58 & 100 \\
\hline
\end{tabular}

Penelitian ini bertujuan untuk melihat hubungan senam lansia dengan kualitas hidup 
lansia yang menderita hipertensi. Penelitian ini menggunakan metode Chi Square dengan hasil yang terlihat pada tabel 5 sebagai berikut:

Tabel 5. Analisis Hubungan Senam Lansia dengan Kualitas Hidup Lansia

\begin{tabular}{|c|c|c|c|c|c|c|}
\hline \multirow{3}{*}{ Senam } & \multicolumn{4}{|c|}{ Kualitas Hidup } & \multirow{3}{*}{ Jlh } & \multirow{3}{*}{$p$-value } \\
\hline & \multicolumn{2}{|c|}{ Baik } & \multicolumn{2}{|c|}{$\begin{array}{c}\text { Sangat } \\
\text { Baik }\end{array}$} & & \\
\hline & $\mathbf{n}$ & $\%$ & $\mathrm{n}$ & $\%$ & & \\
\hline Tidak Senam & 24 & 100 & 0 & 0 & 24 & \\
\hline $\begin{array}{l}\text { Senam Tidak } \\
\text { Rutin }\end{array}$ & 0 & 0 & 32 & 100 & 32 & $<0,001$ \\
\hline Senam Rutin & 0 & 0 & 2 & 100 & 2 & \\
\hline
\end{tabular}

Berdasarkan tabel di atas dapat disimpulkan bahwa terdapat hubungan antara senam lansia terhadap kualitas hidup lansia yang menderita hipertensi.

\section{PEMBAHASAN}

Berdasarkan hasil penelitian Riset Kesehatan Dasar (2013), didapatkan bahwa usia responden pada penelitian ini yaitu 60 tahun sampai 78 tahun. Untuk melihat distribusi usia responden dalam penelitian ini, peneliti mengelompokkan usia responden menjadi 4 kelompok dari seluruh total responden yang berjumlah 58 orang, yaitu kelompok usia 60-64 tahun sebanyak 23 orang (40\%), kelompok usia 65-69 tahun sebanyak 25 orang (42\%), kelompok usia 70-74 tahun sebanyak 8 orang (14\%) dan kelompok usia 75-79 tahun sebanyak 2 orang (4\%). Di Indonesia pada tahun 1999, proporsi penduduk berusia 60-64 tahun besarnya 2,9\%, kelompok berusia 65-69 tahun sebesar 2,3\%, kelompok berusia $70-74$ tahun $1,4 \%$ dan penduduk dengan usia 75 tahun atau lebih 1,4\%. Pada tahun 2012 Indonesia mengalami penurunan jumlah penduduk lansia, pada tahun 2009 penduduk lansia sebanyak 8,37\% dari seluruh penduduk Indonesia, sedangkan pada tahun 2012 jumlah penduduk lansia mengalami penurunan menjadi $7,56 \%$. Penduduk lansia merupakan salah satu indikator keberhasilan pencapaian pembangunan manusia secara global dan nasional, keadaan ini berkaitan dengan adanya perbaikan kualitas kesehatan dan kondisi sosial masyarakat yang meningkat (Kemenkes, 2013).

Berdasarkan penelitian Riset Kesehatan Dasar (2013) yang telah dilakukan dapat diketahui bahwa dari 58 responden laki-laki dan perempuan yang memiliki riwayat hipertensi terbanyak adalah perempuan yaitu sebanyak 44 orang atau sekitar $76 \%$, sedangkan penderita hipertensi pada laki-laki sebanyak 14 orang atau 24\%. Prevalensi hipertensi berdasarkan jenis kelamin pada tahun 2007 dan tahun 2013 menunjukkan perempuan memiliki angka prevalensi yang lebih tinggi dibandingkan dengan laki-laki. Menurut hasil Riskesdas tahun 2013, penyakit hipertensi lebih banyak diderita oleh pempuan yaitu sebesar $28,8 \%$, sedangkan laki-laki sebanyak $22,8 \%$.

Senam lansia merupakan salah satu upaya untuk meningkatkan kesegaran jasmani kelompok lansia yang jumlahnya semakin bertambah, sehingga perlu diberdayakan dan dilaksanakan secara benar, teratur, dan rutin. Senam lansia dapat membantu kekuatan pompa jantung agar bertambah, sehingga aliran darah bisa kembali lancar, dikarenakan pada usia lanjut kekuatan mesin pompa jantung berkurang, dan berbagai pembuluh darah penting khusus di jantung dan otak mengalami kekakuan (Isesreni \& Minropa, 2011). Senam lansia merupakan rangkaian gerakan yang dirancang khusus bagi lanjut usia. Gerakan-gerakan yang dilakukan pada senam lansia tidak bersifat high impact tetapi low impact yang merupakan rangkaian gerakan kegiatan sehari-hari dengan dipadukan musik yang lembut dan tidak menghentak-hentak yang menimbulkan suasana santai. Gerakan otot yang dipilih adalah gerakan yang tidak terlalu menimbulkan beban dan setiap gerakan dibatasi delapan sampai enam belas kali hitungan serta cukup baik bila dilakukan secara teratur dua sampai tiga kali seminggu. Senam lansia dibuat khusus untuk membantu lansia agar dapat mencapai usia lanjut yang sehat, berguna, bahagia, dan sejahtera. Program senam lansia diarahkan pada pembentukan lansia yang sehat dinamis, yaitu mempunyai kemampuan gerak, mampu mendukung segala kegiatan, dan kreativitas bagi peningkatan kesejahteraan hidup lansia. Senam lansia tidak hanya sekedar menjaga kesehatan pada lansia, tetapi tetapi tercapainya lansia yang sehat fisik, mental, dan sosial (Tegawati, karini \& Widya, 2009). Berdasarkan penelitian yang telah dilakukan dapat diketahui bahwa dari 58 responden sebanyak 24 orang (41\%) tidak melakukan senam sama sekali dalam satu bulan terakhir. Sedangkan sebanyak 32 orang (55\%) melakukan senam secara tidak rutin dalam satu bulan terakhir dan sebanyak 2 orang (4\%) melakukan senam secara rutin.

Kualitas hidup lansia adalah tingkat kesejahteraan dan kepuasan dengan peristiwa atau kondisi yang dialami lansia, yang dipengaruhi penyakit atau pengobatan. Kualitas 
hidup lansia bisa didapatkan dari kesejahteraan hidup lansia, emosi, fisik, pekerjaan, kognitif dan kehidupan sosial (Fogari, 2004). Menurut Pangkahila (2013), kualitas hidup lansia meliputi: (1) Ranah fisik: yang meliputi kenyamanan, energi, kelelahan dan istirahat (2) Psikososial: yang mencakup perasaan positif dan negatif, harga diri, citra tubuh dan penampilan diri (3) Tingkat independensi: yang meliputi aktifitas fisik, ketergantungan obat dan kapasitas kerja (4) Hubungan sosial: yang meliputi: hubungan pribadi, dukungan sosial, aktivitas seksualitas (5) Lingkungan: lansia berkesempatan mendapatkan informasi. (6) Spiritual.

Penurunan kualitas hidup dialami oleh beberapa orang dikarenakan faktor kesehatan fisik, salah satunya adalah penyakit yang dimiliki oleh orang tersebut dalam hal ini lansia. Hipertensi adalah salah satu penyebab penurunan kualitas hidup pada lansia. Penyakit kardiovaskular akibat hipertensi dapat menyebabkan masalah pada kualitas hidup lanjut usia, sehingga kualitas hidup para lanjut usia akan terganggu dan angka harapan hidup lansia juga akan menurun (DegI'nocenti, et al., 2004). Kualitas hidup individu yang menderita hipertensi lebih buruk dibandingkan dengan individu yang memiliki tekanan darah normal. Hal tersebut dipengaruhi oleh tekanan darah dan tingkat kesadaran seseorang tersebut (Trevissol, 2011). Berdasarkan penelitian yang telah dilakukan dan hasil yang sudah di olah dalam program aplikasi komputer diketahui bahwa lansia yang tidak melakukan senam yaitu sebanyak 24 orang $(41 \%)$ memiliki kualitas hidup baik dengan skor antara 60-90, lalu lansia yang melakukan senam lansia tidak rutin dalam satu bulan terakhir sebanyak 32 orang (53\%) serta lansia yang melakukan senam lansia secara rutin sebanyak 2 orang (4\%) memiliki kualitas hidup yang sangat baik dengan skor lebih dari 90 . Uji statistik yang digunakan pada penelitian ini adalah dengan menggunakan metode Chi Square didapatkan hasil $p$-value $<\alpha \quad(\alpha=0,05), \quad \mathrm{Hal}$ tersebut dapat diartikan bahwa senam lansia memiliki hubungan dengan kualitas hidup lansia yang menderita hipertensi di Klinik swasta Kedaton Bandar Lampung.

\section{DAFTAR PUSTAKA}

Chobanian, A. V. et al. 2003. Seventh report of the Joint National Committee on Prevention, Detection, Evaluation, and Treatment of High Blood Pressure. New
Hasil tabulasi ini menunjukkan bahwa lansia yang tidak melakukan senam memiliki kualitas hidup yang baik, sedangkan lansia yang melakukan senam lansia memiliki kualitas hidup yang sangat baik. Menurut Chobanian et al., (2003), senam lansia menjadi salah satu aktivitas fisik yang dapat dilakukan untuk mengurangi peningkatan tekanan darah dan memperbaiki kualitas hidup yang terjadi pada penderita hipertensi. Penyakit kardiovaskular akibat hipertensi dapat menyebabkan masalah pada kualitas hidup lanjut usia, sehingga kualitas hidup para lanjut usia akan terganggu dan angka harapan hidup lansia juga akan menurun. Lanjut usia dapat dinyatakan memiliki tingkat kualitas hidup yang baik, bila suatu kondisi yang menyatakan tingkat kepuasan secara batin, fisik, sosial, serta kenyamanan dan kebahagiaan hidupnya (DegI'nocenti, et al., 2004). Kualitas hidup pada penderita hipertensi lebih rendah dalam delapan domain dari kuisioner SF-36, diantaranya adalah fungsi fisik, fungsi fungsional, peran fisik, emosional, nyeri tubuh, kesehatan umum, vitalitas, dan kesehatan mental. Hipertensi berhubungan dengan rendahnya kualitas hidup, terutama dalam domain fungsi fisik (Soni et al., 2010).

Peningkatan kualitas hidup secara mental yang diperoleh melalui aktivitas fisik adalah penurunan tingkat stres, meningkatkan rasa antusias dan rasa percaya diri, serta penurunan kecemasan dan depresi seseorang terkait dengan penyakit yang dialaminya (Taylor, Sallis \& needle,1985). Peningkatan aktivitas fisik yang teratur dalam hal ini olahraga menunjukkan penurunan pada dua mood yaitu kecemasan dan depresi (Folkin,1976) Olahraga tertentu dapat menghasilkan substansi yang meningktkan mood pada pasien dengan mayor depresi dalam waktu singkat (Dimeo, et al., 2001)

\section{SIMPULAN}

Terdapat hubungan antara senam lansia dengan kualitas hidup lansia yang menderita hipertensi.
York: U.S Department of Health and Human Services. hal: 1206-1252.

Degl'Innocenti, a et al. 2004. Health-related quality of life during treatment of elderly patients with hypertension: results from the 
Study on COgnition and Prognosis in the Elderly (SCOPE). Journal of human hypertension. 18(1): 239-245.

Dimeo, F. et al. 2001. Benefit from Aerobic Exercise Inpatient with Major Depression: A Pilot Study. British Journal of Sport Medicine. 35(1): 114-117.

Folkin, CH.1976. Effect of Physical Training on Mood. Journal of Clinical Psichology NCBI. 32(2): 385-388.

Fogari, R. \& A, Z. 2004. Effect of antihypertensive agents on quality of life in the elderly. Nationa Center for Biotechnology Information. [diakses 27 Oktober 2015]. Tersedia dari: http://www.ncbi.nlm.nih.gov/pubmed/150 84140.

Isesreni \& Minropa, A. 2011. Pengaruh Senam Lansia Terhadap Penurunan Tekanan Darah Pada Lansia Hipertensi di RW II, $R W X I V$, dan RW XXI Kelurahan Surau Gadang Wilayah Kerja Puskesmas Nanggalo Padang Tahun 2011 [Tesis]. Padang: Stikes Mercubaktijaya.

Kementerian Kesehatan, RI. 2013. Hasil Riset kesehatan Dasar. Jakarta: Direktorat Jendral Bina Kesehatan Masyarakat Departemen Kesehatan RI.

Kementerian Kesehatan, RI. 2013. Hipertensi. pada Infodatin (Pusat Data dan Informasi Kementerian Kesehatan RI). Jakarta: Kementerian Kesehatan Republik Indonesia. hal. 1-8.

Notoatmodjo, S., 2010. Metodologi Penelitian Kesehatan, Jakarta: Rineka Cipta.

Setiawan, G.W., Wungouw, H.I.S. \& Pangemanan, D.H.C. 2013. Pengaruh Senam Bugar Lanjut Usia (Lansia) Terhadap Kualitas Hidup Penderita Hipertensi. Jurnal e-Biomedik (eBm). 1(2): 760-764.
Soni, R.K. et al. 2010. Health-Related Quality of Life in Hypertension, Chronic Kidney Disease, and Coexistent Chronic Health Conditions. Journal of Advances in Chronic Kidney Disease. 17(4): 17-26.

Suardana, W.I., Saraswati, N.L.G.I. \& Wiratni, M. 2010. Dukungan Keluarga dan Kualitas Hidup Lansia Hipertensi. Denpasar, Bali.

Suhardjono, 2009. Hipertensi Pada Lanjut Usia. Pada A. W. Sudoyo et al., eds. Buku Ajar Ilmu Penyakit Dalam. Jakarta: Interna Publishing. hal. 899-903.

Syahrini, E.N., Susanto, H.S. \& Udiyono, A. 2012. Faktor-Faktor Risiko Hipertensi Primer di Puskesmas Tlogosari Kulon Kota Semarang. Jurnal Kesehatan Masyarakat. 1(2): 1-11.

Taylor, C.B., Sallis, J.F. \& Needle, R. 1985. The relation of physical activity and exercise to mental health. Journal of Public health reports. 100(2): 195-202

Tegawati, L.M., Karini, S.M. \& Widya, R. 2009. Pengaruh Senam Lansia Terhadap Penurunan Tingkat Depresi Pada Orang Lanjut Usia. Jurnal Psikologi. 1(2): 36-45.

Trevisol, D.J. et al., 2011. Health-related quality of life and hypertension: a systematic review and meta-analysis of observational studies. Journal of Hypertension. (Diakses 19 September 2015). Tersedia dari: http://journals.lww.com/jhypertension/Abs tract/2011/02000/Health_related_quality_o f_life_and_hypertension_a.1.aspx.2011:1. http://journals.lww.com/jhypertension/Abs tract/2011/02000/Health_related_quality_o f_life_and_hypertension_a.1.aspx.

Yogiantoro, M. 2009. Buku Ajar Ilmu Penyakit Dalam 5th ed. A. W. Sudoyo et al., eds. Jakarta: Interna Publishing. 